\title{
LA DINÁMICA DEL PAISAJE EN LA SIERRA DEL ARAMO (MACIZO CENTRAL ASTURIANO): PROCESOS NATURALES Y ANTRÓPICOS
}

\author{
The dynamics of landscape in the Aramo Range \\ (Asturian Central Massif): Natural and anthropic processes
}

\author{
Salvador Beato Bergua*, Miguel Ángel Poblete Piedrabuena, José Luis Marino Alfonso \\ Departamento de Geografía, Universidad de Oviedo. 33011-Oviedo (Asturias). \\ Identificador ORCID de los autores y e.mail \\ Salvador Beato Bergua: http://orcid.org/0000-0001-5538-7685. E-mail: uo187213@uniovi.es \\ Miguel Ángel Poblete Piedrabuena: http:// orcid.org/0000-0003-1030-5310. E-mail: mpoblete@uniovi.es \\ José Luis Marino Alfonso: http:// orcid.org/0000-0001-6213-407X. E-mail: jolumarino@gmail.com \\ *Autor corresponsal
}

\begin{abstract}
Recibido: 14-11-2018. Aceptado: 6-02-2019. Fecha de publicación on-line: 26/03/2019
Citation / Cómo citar este artículo: Beato Bergua, S., Poblete Piedrabuena, M.Á., Marino Alfonso, J.L. (2019). La dinámica del paisaje en la Sierra del Aramo (Macizo Central Asturiano): procesos naturales y antrópicos. Pirineos, 174, e041. https://doi.org/10.3989/pirineos.2019.174001

RESUMEN: Se analizan los procesos naturales y antrópicos que intervienen en la dinámica del paisaje de la Sierra del Aramo, en especial la dinámica de laderas y el calentamiento atmosférico, así como el despoblamiento y los cambios de usos del suelo en los medios de montaña. La metodología ha combinado el trabajo de campo, la fotointerpretación de imágenes aéreas, el análisis de datos climáticos, fuentes demográficas y agrarias. El despoblamiento y el abandono de las actividades tradicionales explican la disminución de los pastizales. No obstante, la intensidad de los aludes de nieve actuales interfiere en buena medida en la recuperación de los bosques. En efecto, $3,7 \mathrm{~km}^{2}$ de la Sierra del Aramo se hallan deforestados por la recurrencia de tales avalanchas. Se muestra, por tanto, la relevancia de los aludes de nieve en la dinámica del paisaje de las montañas medias en las latitudes templadas.
\end{abstract}

PALABRAS CLAVE: Áreas de montaña; cubierta forestal; despoblamiento; cambios de usos del suelo; calentamiento atmosférico; aludes de nieve; Macizo Asturiano.

\begin{abstract}
The natural and anthropic processes that intervene in the landscape dynamics of the Sierra del Aramo are analyzed. Particularly, we focus on the analysis of slope dynamics and climate warming, as well as the depopulation and changes of land uses in mountain environments. The methodology has combined field work, imagery and climate data analyses, as well as demographic and agrarian sources. The depopulation and abandonment of traditional activities explain the decline of pastures. However, the intensity of the current snow avalanches prevents the reforestation in some slopes. In the Sierra del Aramo $3.7 \mathrm{~km}^{2}$ are deforested by the recurrence of such avalanches. The relevance of snow avalanches in the dynamics of the landscape of the middle mountains in temperate latitudes are revealed.
\end{abstract}

KEY WORDS: Mountain areas; forest cover; depopulation; changes in land uses; atmospheric warming; snow avalanches; Asturian Massif. 


\section{Introducción}

Entre los procesos naturales y antrópicos que determinan el devenir de la dinámica del paisaje en los medios de montaña cabe destacar, entre otros, la dinámica de laderas y más concretamente el desencadenamiento de aludes de nieve, así como los efectos derivados del despoblamiento y los cambios de usos del suelo. En efecto, los aludes de nieve son uno de los principales procesos nivales que actúan en la dinámica y evolución de los medios de montaña de todo el mundo (Luckman, 1978; Butler, 1985; Schweizer et al., 2003). En concreto, ejercen una influencia decisiva en la configuración del paisaje de las montañas, puesto que no sólo incrementan los procesos geomorfológicos, sino que además afectan a las franjas forestal y supraforestal de los pisos geoecológicos sometidos a sus perturbaciones (Pattern \& Knight, 1994; Sawyer \& Butler, 2006; Rixen et al., 2007; Bebi et al., 2009; Kulakowski, et al., 2011; Giacona et al., 2018).

En España, la mayoría de las investigaciones efectuadas sobre los aludes de nieve se han llevado a cabo en los Pirineos (Furdada et al., 1995; García et al., 2009; Muntán et al., 2009, 2010; Chueca \& Julián, 2010) y, en menor medida, en el Sistema Central (Fernández-Cañadas, 2014). Cabe destacar las tesis doctorales de Muñoz Trigo (1988), por su carácter pionero en la prevención y defensa contra aludes, y la recientemente defendida por Muntán (2016) en el ámbito de la dendrogeomorfología. En la Cordillera Cantábrica no son muchos los trabajos realizados hasta el momento, distinguiéndose dos tipos de investigaciones: por un lado, las de carácter geomorfológico (Castañón, 1984; González \& Serrano, 2010) y, por otro, las que abordan el riesgo y peligrosidad de los aludes de nieve basados en noticias de prensa (García-Hernández et al., 2017) o en mapas de susceptibilidad (Marquínez et al., 2003; Beato et al., 2018). Así mismo, cabe destacar los trabajos de Santos et al. (2010) sobre el peligro de aludes en el Alto Sil, Vada et al. (2012) en el Macizo Central de los Picos de Europa, Serrano et al. (2016) en el Alto Carrión y, finalmente, el análisis de Poblete et al. (2016) que aborda la susceptibilidad y peligrosidad de las avalanchas de nieve sobre la carretera AS-253 que asciende al Puerto de San Isidro. En ellos no se analizan los efectos perturbadores de las avalanchas de nieve sobre los paisajes forestales; además la mayoría se centran en las zonas de alta montaña de la Cordillera Cantábrica, dejando a un lado las montañas de altitud media que apenas han sido estudiadas.

El despoblamiento y los cambios de usos del suelo acaecidos en los medios de montaña a partir de mediados del siglo XX han producido una disminución notable de los pastizales $y$, por contra, un crecimiento significativo de las superficies de matorral y de bosque (Molinillo et al., 1997; Vicente-Serrano, 2001; Sanz-Elorza et al., 2003; Lasanta et al., 2005; Roura-Pascual et al., 2005; Bengoa, 2011; Lallana \& González, 2012). Las consecuencias de este proceso también se han producido en el Macizo Asturiano (Martínez, 2016) y, por supuesto, en la Sierra del Aramo (Beato et al., 2016).
Por otro lado, el aumento de las temperaturas debido al cambio climático no solo contribuye a la matorralización y reforestación, sino que también afecta a otros procesos ecológicos montanos como el desencadenamiento de aludes de nieve húmeda (Naaim et al., 2016; Schläppy et al., 2016; Muntán, 2016). Así, el calentamiento global está incrementando este tipo de amenaza con repercusión sobre las cubiertas forestales y las infraestructuras (Ballesteros-Cánovas et al., 2018; Heffernan, 2018).

Los objetivos fundamentales de este estudio son: i) analizar los efectos del despoblamiento y de los cambios de usos de suelo en la evolución y estructura del paisaje forestal en la Sierra del Aramo desde 1960 hasta nuestros días; ii) examinar los efectos del calentamiento atmosférico en la nivosidad y en la formación de las avalanchas de nieve; iii) conocer y determinar cómo los cambios de usos de suelo y las avalanchas de nieve han afectado a la dinámica del paisaje de una montaña media atlántica.

\section{2. Área de estudio}

El Macizo Asturiano constituye el sector occidental de la Cordillera Cantábrica, que se extiende de forma paralela a la costa septentrional española a lo largo de $220 \mathrm{~km}$ en el extremo NW de la Península Ibérica y alcanza una superficie de casi $18.000 \mathrm{~km}^{2}$ (Muñoz \& Sanz, 1995). Dicho macizo se compone de tres unidades: occidental, central y oriental. La unidad seleccionada para el estudio, la Sierra del Aramo, es una de las principales montañas medias del Macizo Central Asturiano, situada a unos $20 \mathrm{~km}$ al SW de Oviedo. Se trata de una montaña de altitud media (Pico Gamoniteiru, 1.791 m s.n.m. y Xistras, 1.766 m s.n.m.) y de litología mayoritariamente calcárea, que se extiende en dirección NNW-SSE a lo largo de unos $15 \mathrm{~km}$ de longitud, separando las cuencas de los ríos Trubia al W y Caudal al E. Se caracteriza por disponer además de una plataforma culminante por encima de los 1.500-1.600 m, en la que los procesos kársticos han modelado una superficie repleta de dolinas, pozos nivales y con presencia de varios valles muertos y cumbres en resalte (Figura 1).

Desde el punto de vista geológico, la Sierra del Aramo pertenece a la Zona Cantábrica, en concreto, a la Región de Pliegues y Mantos. Está formada por materiales paleozoicos carbonatados y siliciclásticos que han sido plegados y fracturados durante las orogenias varisca y alpina, destacando las potentes escamas de calizas namurienses elevadas sobre los materiales del carbonífero preestefaniense (Aller, 1993).

Desde el punto de vista climático disfruta de unas condiciones propias del dominio atlántico, esto es, de abundantes precipitaciones, que oscilan entre los 1.100 y 1.500 mm, repartidas a lo largo del año y de temperaturas suaves. No obstante, podemos diferenciar, a grandes rasgos, tres tipos de variantes climáticas a tenor de las modificaciones térmicas que genera el gradiente altitudinal: en primer lugar, entre los 700 y 1.000 m s.n.m. un clima $\mathrm{Cfsb}_{3}$, esto es, templado de transición a fresco con la temperatura media del mes más cálido inferior a $18^{\circ} \mathrm{C}$ y seis meses con una media inferior a $10^{\circ} \mathrm{C}$. Entre los 1.000 y $1.500 \mathrm{~m}$ s.n.m. un 


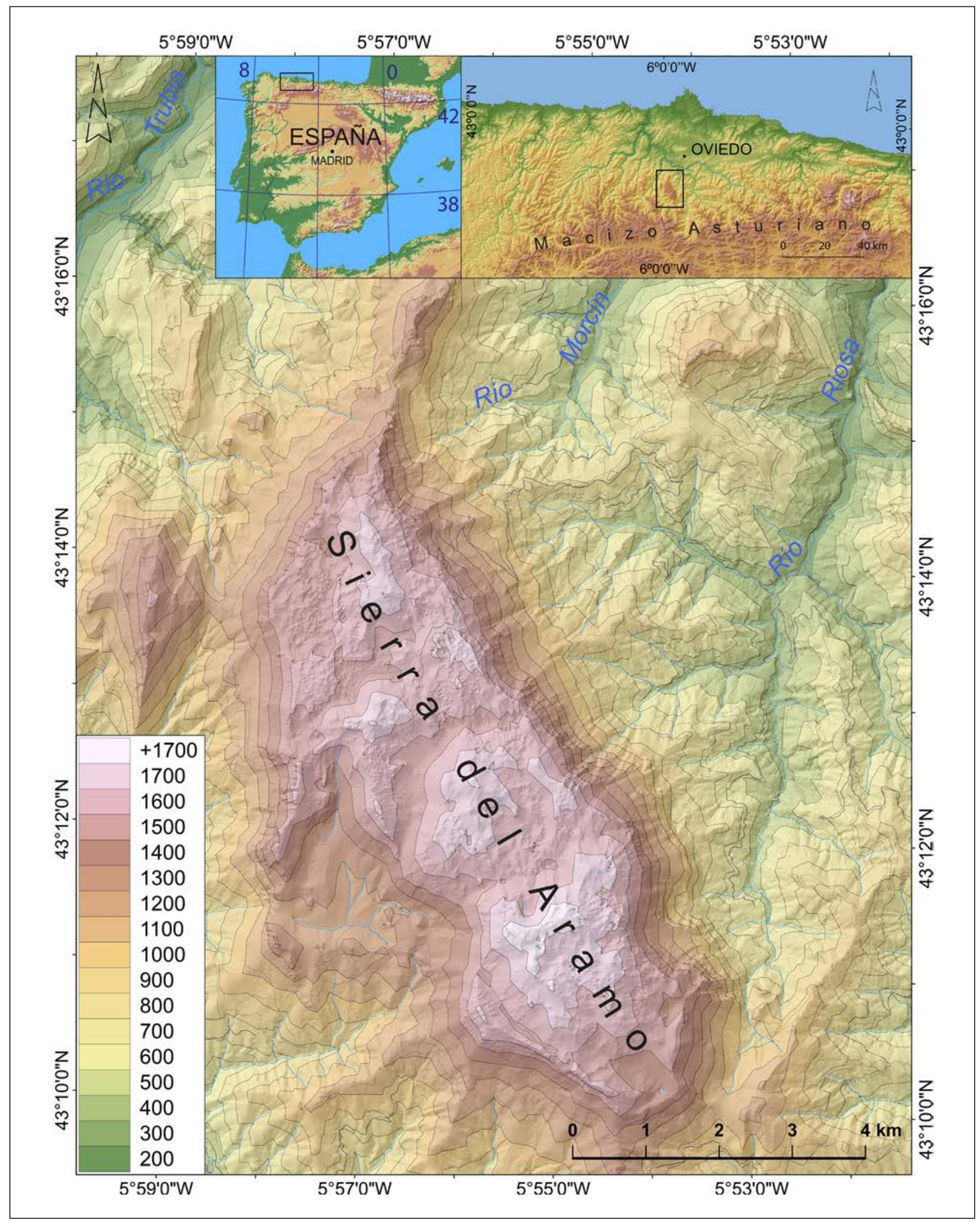

Figura 1: Localización de la zona de estudio. Fuente: Elaboración propia a partir de las bases topográficas digitales del Instituto Geográfico Nacional.

Figure 1: Location of the study area. Source: Own elaboration from the digital topographic bases of the Spanish National Geographic Institute. 
clima propiamente fresco (Cfsc), pues entre ocho y nueve meses alcanzan temperaturas medias inferiores a $10^{\circ} \mathrm{C} \mathrm{y}$, finalmente, por encima de los 1.500 m s.n.m. un clima frío (Dfsc), es decir, de alta montaña con tres a seis meses con temperaturas por debajo de $0^{\circ} \mathrm{C}$ y la mitad de las precipitaciones en forma de nieve (Muñoz, 1982).

El tapiz vegetal de la Sierra del Aramo se caracteriza por la fuerte antropización secular del territorio y por su pertenencia a dos distritos biogeográficos de la Región Eurosiberiana, estos son, los sectores Ovetense y Somedano de las subprovincias Cantabro-atlántica y Orocantábrica respectivamente. Por tanto, se define por formaciones vegetales arbóreas de carácter mixto dominadas por robles o hayas, así como por el aliso en las riberas; y, con mucha mayor extensión, por landas, matorral petrano y pastos en los pisos altimontano y subalpino. Igualmente, están bien representadas las cubiertas de transición entre arbustivas y arborescentes y los bosquetes de baja altura y densidad como las asociaciones de acebos, espinos o escuernacabras (Beato, 2018).

\section{Metodología}

La investigación ha consistido en primer lugar en el trabajo de campo: se procedió a lo largo de diversas jornadas de campo llevadas a cabo entre 2014 y 2018 al recorrido sistemático del macizo calcáreo de la Sierra del Aramo, para reconocer e identificar las principales características de las formas estructurales y de modelado. En concreto, se identificaron gran número de canales de aludes, fundamentalmente concentrados en la vertiente oriental de dicho macizo. Posteriormente, se analizaron las distintas formaciones vegetales a partir de la fotointerpretación de la ortofotografía del PNOA (2015), la realización de herborizaciones (Arozena \& Molina, 2000) y la consulta de todas las fuentes cartográficas referentes a la vegetación (Mapa de vegetación 1:25.000 del Principado de Asturias -INDUROT, 1994-; Mapa forestal de España de máxima actualidad a escala 1:25.000 -MAPAMA, 2018-; Beato, 2018). En concreto, se realizaron 50 inventarios o muestreos aleatorios siguiendo criterios fitosociológicos (Braun-Blanquet, 1979), en cada uno de los cuales se recogieron datos relativos a la orientación, pendiente, situación geomorfológica, sustrato rocoso y características edáficas. Toda la información obtenida fue incorporada a una base de datos georreferenciada y procesada a través de un Sistema de Información Geográfica gestionado por el software ArcGis 10.1, a través del cual se calcularon las superficies de las formaciones vegetales y se confeccionó la cartografía biogeográfica a 1:25.000.

Para el estudio de la evolución de la población de las zonas de montaña y los cambios de usos del suelo se ha recurrido a diversas fuentes. En concreto, el análisis del despoblamiento se ha llevado a cabo a través de la consulta de los censos de población del Instituto Nacional de Estadística de 1900, 1950, 1960, 1970, 1981, 1991, 2001 y 2011. Por otro lado, el estudio de la evolución de las actividades agrarias se ha realizado mediante el análisis de los censos agrarios desde 1962 hasta 2009. El crecimiento de la cubierta forestal de la Sierra del Aramo se ha obtenido mediante el análisis comparativo de los fotogramas aéreos de 1957 y 1985 (previa digitalización y restitución de estos), y de las ortofotografías del PNOA de 2015.

El calentamiento atmosférico en la Sierra del Aramo y sus efectos en la nivosidad, esto es, en la frecuencia e intensidad de las nevadas se ha analizado a partir de los datos pluviométricos de la estación de montaña de Genestoso, situada $40 \mathrm{~km}$ al SW de la Sierra del Aramo a 1.170 m s.n.m., entre 1961 y 2016. Se trata de la única estación meteorológica con una serie climática superior a 30 años y en la que se recogen los datos correspondientes a dicho meteoro. Para el análisis de la tendencia reciente de la nivosidad hemos dispuesto de los datos on-line correspondientes a las estaciones de Aller (750 m s.n.m.) y de Pajares (1.480 m s.n.m.), proporcionados por la Agencia Estatal de Meteorología. Se encuentran a 40 y $25 \mathrm{~km}$ al SE del Aramo, respectivamente, $\mathrm{y}$ ofrecen datos incluso horarios que permiten un seguimiento preciso de las temperaturas y precipitaciones, en condiciones similares a las del área analizada.

Finalmente, el estudio de los episodios de aludes acaecidos en la Sierra del Aramo y sus efectos sobre la vegetación durante los últimos diez años se ha realizado compaginando el trabajo de campo con la fotointerpretación de imágenes aéreas, así como la consulta de hemerotecas (La Nueva España, El Comercio, bases de datos en Internet) y la realización de entrevistas a las poblaciones locales en los concejos de Morcín, Quirós y Riosa (30 entrevistas en las que se preguntó sobre fechas, lugares afectados y daños provocados por aludes, obteniendo resultados similares). En concreto, el trabajo de campo ha consistido en el recorrido de las laderas en varios transectos, tanto longitudinales como transversales, con la finalidad de cartografiar las superficies afectadas por los aludes de nieve y los efectos de estos sobre la cubierta forestal, localizando mediante GPS todos los árboles arrancados, decapitados o con diversos impactos. Con la fotointerpretación geomorfológica de las imágenes aéreas del Vuelo Americano de 1957, del Instituto Geográfico Nacional (1985), del Principado de Asturias de 2003 y de ortofotografías del PNOA de 2006, 2011 y 2015 se ha completado y mejorado la representación cartográfica de las envolventes de los aludes de nieve. También mediante la aplicación de los softwares ArcGis 10.1 y Quantum Gis 2.6 (QGIS) se han analizado, a partir de un modelo digital de terreno (malla de resolución de 5 x $5 \mathrm{~m}$ ), los parámetros que condicionan la estabilidad del manto nival, en especial, altitudes, pendientes y orientaciones.

\section{Resultados}

\subsection{Despoblamiento de las zonas de montaña, cambios en los usos del suelo y crecimiento de la cubierta forestal}

En el sector central del Macizo Asturiano, donde se halla la Sierra del Aramo, el despoblamiento ha sido muy 
acusado al oscilar de una población de 12.338 habitantes en 1960 a 6.285 en 2011, lo que representa una pérdida del $49 \%$ de los efectivos. En la actualidad, esta zona montañosa tiene 92 entidades de población vacías y otras 76 con menos de tres vecinos.

El despoblamiento de las montañas asturianas se produce como resultado de la crisis del sistema de explotación tradicional basado fundamentalmente en actividades agroganaderas. En la Sierra del Aramo, el número de explotaciones agrarias se ha reducido drásticamente en un $77,2 \%$, disminuyendo de 2.600 en 1962 a 593 en 2009. Por otro lado, la cabaña ganadera también ha decrecido de 12.122 cabezas en 1999 a 8.005 en 2009, esto es, un $33,9 \%$.

Como resultado se produce un cambio significativo en los usos del suelo que se inicia en los años setenta, con el paso de una economía tradicional de subsistencia agroganadera muy diversificada a una monoproducción ganadera exclusivamente vacuna y de explotación semiextensiva basada en la producción cárnica. En concreto, en la Sierra del Aramo se aprecia una reducción drástica de la superficie de pastos que ha pasado de 4.396 ha $(30,1 \%$ del total del territorio) en 1957 a $1.883,6(12,9 \%)$ en 2015 , lo que representa una disminución de un $17,2 \%$, afectando principalmente a las laderas. Por el contrario, el matorral ha aumentado de $2.630,5$ ha $(18 \%)$ en 1957 a $4.140,1$ ha $(28,4 \%)$ en 2015 , un incremento, pues, de $1.509,6$ ha $(10,3 \%)$. Por último, los bosques y bosquetes (pequeñas formaciones arborescentes poco densas) también han aumentado en el mismo periodo de tiempo $2.597,1$ ha, pasando de 3.012,2 (20,6\%) a $5.609,3$ ha $(38,4 \%)$, lo que representa un incremento del $17,8 \%$ respecto a la superficie total (Figura 2).

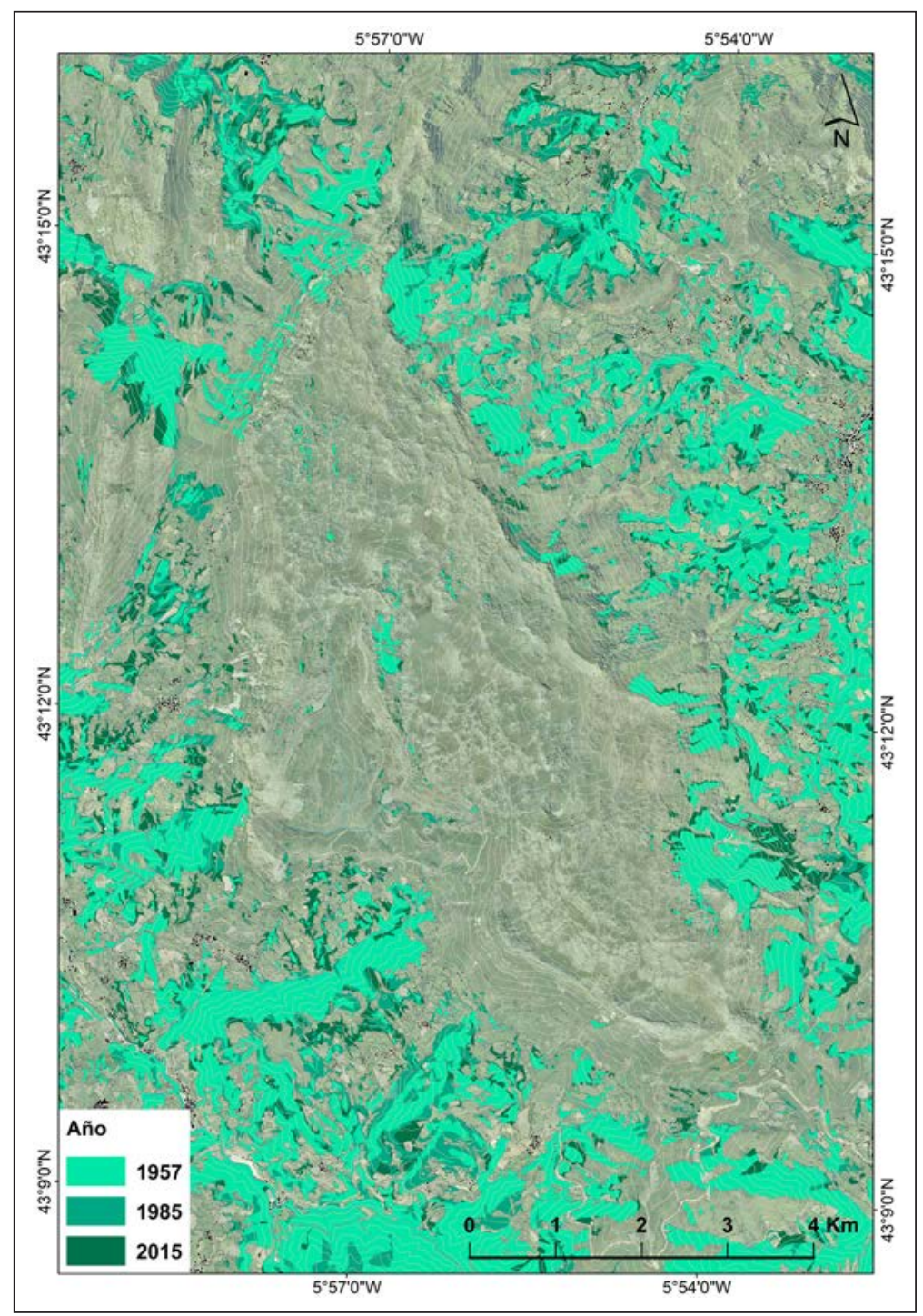

Figura 2: Evolución de la cubierta forestal en la Sierra del Aramo. Fuente: Elaboración propia. Ortofotomapas del PNOA y bases topográficas digitales del Instituto Geográfico Nacional.

Figure 2: Evolution of the forest cover in the Sierra del Aramo. Source: Own elaboration. Ortophotomaps and digital topographic bases of the Spanish National Geographic Institute. 
En concreto, los bosques avanzan de forma ininterumpida sobre las áreas colonizadas por las formaciones arbustivas y arborescentes. En especial, las vertientes muestran un mosaico formado por densas forestas (asociaciones mixtas de planocaducifolias y hayedos principalmente), bosques jóvenes de abedul, arce, fresno, etc. y formaciones arbustivas con avellanos, endrinos, espineras y arraclanes. También hay extensas acebedas ( $\mathrm{Sa}$ niculo europaeae-Ilicetum aquifolii) que, beneficiadas por la vigente protección, van cubriendo espacios clareados que potencialmente corresponden al haya. Por su parte, los diferentes matorrales tienen un papel protagonista en el paisaje configurando helechales de Pteridium aquilinum, en buena medida acompañado de zarzas $(R u$ bus sp.pl.), y aulagares de Genista hispanica ssp. occidentalis con el tojo (Ulex europaeus) o con el brezo (Erica vagans).

\subsection{El calentamiento atmosférico y la nivosidad en las montañas medias del Macizo Asturiano}

El clima del Macizo Asturiano está experimentado, al igual que el resto del planeta, un incremento térmico progresivo de la atmósfera que se ha intensificado a partir de los años 80 del siglo pasado. En concreto, Álvarez et al. (2009) han comprobado un aumento constante y homogéneo de la temperatura atmosférica, más pronunciado en primavera y verano y con especial incidencia en las temperaturas máximas, que se traduce en un incremento medio de $0,21^{\circ} \mathrm{C}$ por década a lo largo del período 1961 2007. No obstante, en dicho trabajo no se analiza la evolución de la nivosidad, por lo que tampoco se evalúa el efecto que dicho calentamiento está teniendo directamente en la frecuencia e intensidad de las nevadas e indirectamente sobre el desencadenamiento de los aludes de nieve en el Macizo Asturiano.

La prueba más evidente que constata que se está produciendo algún cambio en las condiciones climáticas debido al calentamiento global es el estudio de la tendencia temporal de las nevadas caídas en la estación de Genestoso. En la serie temporal disponible se comprueba una clara tendencia decreciente tanto en el cómputo global de las precipitaciones sólidas como en el número de días en que nieva, que ha sido calculada a través de la regresión lineal. Entre 1961-2016 la nivosidad disminuye a razón de $64,8 \mathrm{l} / \mathrm{m}^{2}$ por decenio (Figura 3 ), mientras que el número de días en que nieva desciende 5,1 por decenio.

No obstante, en la figura 3 se aprecia un cambio de tendencia en la serie temporal a partir del año 2000, por

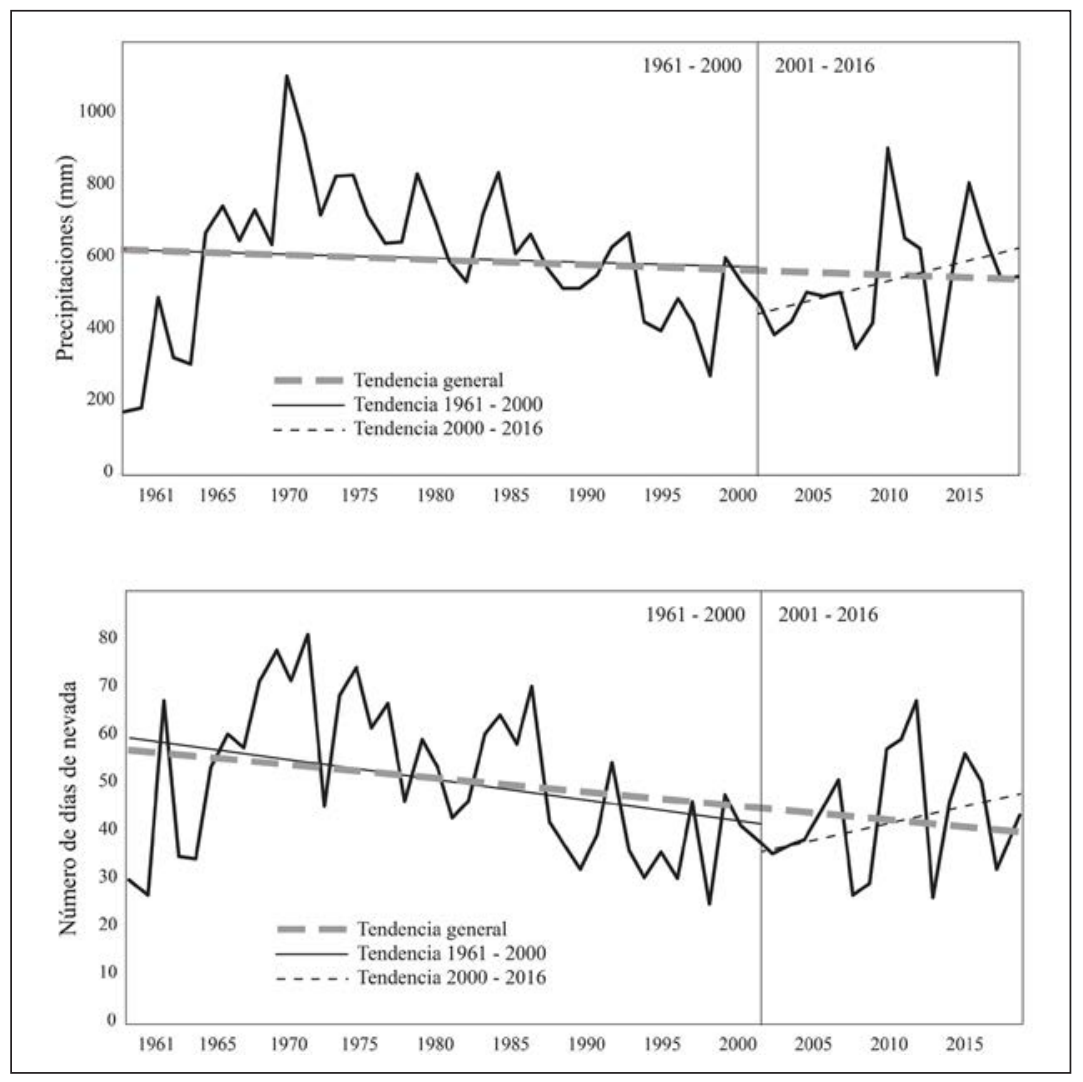

Figura 3: Evolución de la nivosidad y de los días de nevada desde 1961 hasta 2016. Fuente: Elaboración propia a partir de los datos de la estación meteorológica de Genestoso (AEMET). Figure 3: Evolution of the snowfall and snow days from 1961 to 2016. Source: Own elaboration from the data of the meteorological station of Genestoso (AEMET). 
lo que es aconsejable dividir la serie en dos tramos para estudiarlos separadamente. La tendencia entre 19612000 tiene un ajuste más preciso $\left(\mathrm{R}^{2}=0,6254\right)$ y la pendiente es mucho más acusada con un descenso de las nevadas de $157,51 / \mathrm{m}^{2}$ por decenio, en tanto que el número de días de nevada disminuye a un ritmo de 12,3 por decenio. Por otro lado, entre 2001-2016 la tendencia, aunque la serie temporal es corta, revela un repunte de la nivosidad con un incremento de las precipitaciones en forma de nieve de $132,21 / \mathrm{m}^{2}$ por decenio, al tiempo que un aumento del número de días de nieve, en concreto, 5 cada decenio.

Pese a dicho repunte (que hay que tomarlo con cautela dada la corta serie temporal), las nevadas y el número de días con nieve, sin embargo, han disminuido notablemente si comparamos los periodos 1961-2000 y 20012016, pasando de un promedio de $634,91 / \mathrm{m}^{2}$ y 50 días a $544,51 / \mathrm{m}^{2}$ y 43,4 días respectivamente. Además de la variabilidad de los valores de las nevadas entre 2001 y 2016 hemos podido documentar también que en los últimos años la nivosidad tiene lugar de forma muy concentrada y copiosa. En efecto, las nevadas se producen en episodios del orden de 5 o 6 días y con intensidades que superan en ocasiones los $30 \mathrm{l} / \mathrm{m}^{2}$ en $24 \mathrm{~h}$, representando en ocasiones la mitad de la totalidad de las precipitaciones en forma de nieve. Cabe destacar, como ejemplos, los episodios acontecidos en la estación meteorológica de Aller entre los días 18 y 22 de enero de 2015, durante los cuales cayeron un total de $145,8 \mathrm{~mm}$ de nieve (el 21 de enero se alcanzaron $34,2 \mathrm{~mm}$ de nieve); entre el $1 \mathrm{y}$ el 6 de febrero del mismo año cayeron otros 116,2 mm de nieve (el 3 de febrero se registraron $34,8 \mathrm{~mm}$ de nieve). En el año 2016 se registraron en Aller otros episodios de copiosas nevadas: entre los días 26 y 28 de febrero cayeron $991 / \mathrm{m}^{2}$ (el 27 de febrero se registraron 40,2 $\mathrm{mm}$ de nieve); los días 5, 6 y 7 de noviembre de ese mismo año volvieron a caer $104 \mathrm{l} / \mathrm{m}^{2}$ (el 6 de noviembre se registraron 40,4 $\mathrm{mm}$ de nieve). Tales nevadas, resultantes de la entrada por el N y NW de familias o de sucesivas borrascas de aire húmedo y frío polar, producen importantes acumulaciones de nieve que se traducen en mantos nivales de más de un metro de espesor a apenas $1.000 \mathrm{~m}$ s.n.m., lo que favorece que se den las condiciones adecuadas para el desencadenamiento de aludes de nieve, tanto en la alta montaña como también en las de media altitud, esto es, entre 1.000 y $1.700 \mathrm{~m}$.

Los resultados obtenidos del análisis de la evolución de la nivosidad en el Macizo Asturiano tienen sólo un carácter orientativo debido a la escasez de estaciones meteorológicas de montaña y a la falta de observaciones precisas sobre este tipo de meteoros hasta fechas muy recientes. No obstante, se aprecia que la tendencia de las nevadas es a producirse en episodios muy concentrados y con una elevada intensidad, que superan con frecuencia los $30 \mathrm{~mm}$ en $24 \mathrm{~h}$, que facilitan la formación recurrente de aludes de nieve. De hecho, es un criterio clásico, para definir escenarios de aludes, tomar los valores de precipitación de nieve reciente en $72 \mathrm{~h}$ como espesor de nieve movilizable (Burkard \& Salm, 1992).

\subsection{La actividad de los aludes de nieve y sus efectos en la estructura y distribución de la cubierta forestal}

Como en el resto del Macizo Asturiano, el despoblamiento de la Sierra del Aramo, a partir de la segunda mitad del siglo XX, y la crisis del sistema de explotación tradicional agroganadero han favorecido la expansión del matorral y del bosque en su territorio. Sin embargo, dicha recuperación no se ha producido en todas las vertientes, en concreto, la vertiente oriental de la Sierra del Aramo, que tiene una extensión aproximada de 1.554 ha, presenta una evidente anomalía forestal pues predominan en ella los pastizales (Beato et al., 2017).

Uno de los rasgos geomorfológicos más destacables de la vertiente oriental de la Sierra del Aramo es que se halla surcada por numerosos canales de aludes, algunos tan marcados como El Reguerón y el Arguixu La Yampa. Por otro lado, los canales de El Reguerón y de El Espinial exhiben una red dendrítica de canales tributarios, en disposición ortoclinal, que aprovechan la alternancia litológica de las formaciones Candamo-Baleas y Alba (las bandas de pizarras, arcillas y margas), merced a la superposición de pequeñas escamas cabalgantes. En general, los canales se inician a la salida de nichos de nivación, adoptando una disposición rectilínea y una estructura interna en forma de tobogán, mientras que en la zona de llegada configuran pequeñas pedreras o incluso grandes conos de bloques y derrubios. También se han modelado pequeños canales en los afloramientos rocosos superiores, de los que parten para abrirse o juntarse con otros situados ladera abajo propiciando así la acumulación de canchales. En total, hemos identificado un centenar de canales de aludes, muchos de los cuales siguen activos actualmente y algunos de ellos, como El Reguerón, el Arguixu La Yampa y El Espinial, pueden catalogarse como de gran tamaño pues tienen una longitud superior a 1.000 m (McClung \& Schaerer, 2006) (Figura 4). No obstante, la media de los canales es de $286,5 \mathrm{~m}$ de longitud (Tabla 1), por tanto, tienen unas dimensiones medianas, esto es, comprendidas entre 100 y 1.000 m (McClung \& Schaerer, 2006).

El desencadenamiento de los aludes de nieve en la Sierra del Aramo responde básicamente a tres factores principales: la intensa nivosidad, orientación a sotavento de las borrascas del N y NW y las fuertes pendientes. Estos factores son los responsables del desencadenamiento de los aludes de nieve en todo el Macizo Asturiano (Marquínez et al., 2003; Wozniak \& Marquínez, 2004) y especialmente en las montañas medias (Poblete et al., 2016). Cada año se producen del orden de 4 ó 5 temporales de nieve distribuidos entre octubre y abril. Se trata de temporales con una duración media entre 3 y 5 días con nevadas muy intensas que superan los 30 y $40 \mathrm{~mm}$ de nieve en sólo $24 \mathrm{~h}$, los cuales originan mantos nivales significativos del orden de más de $1 \mathrm{~m}$ de espesor a partir de $1.000 \mathrm{~m}$ s.n.m. e innivaciones de 5 a 7 meses. En concreto, la entrada por el NW y el N de borrascas de aire húmedo y frío polar producen importantes acumulaciones de nieve en la plataforma culminante 


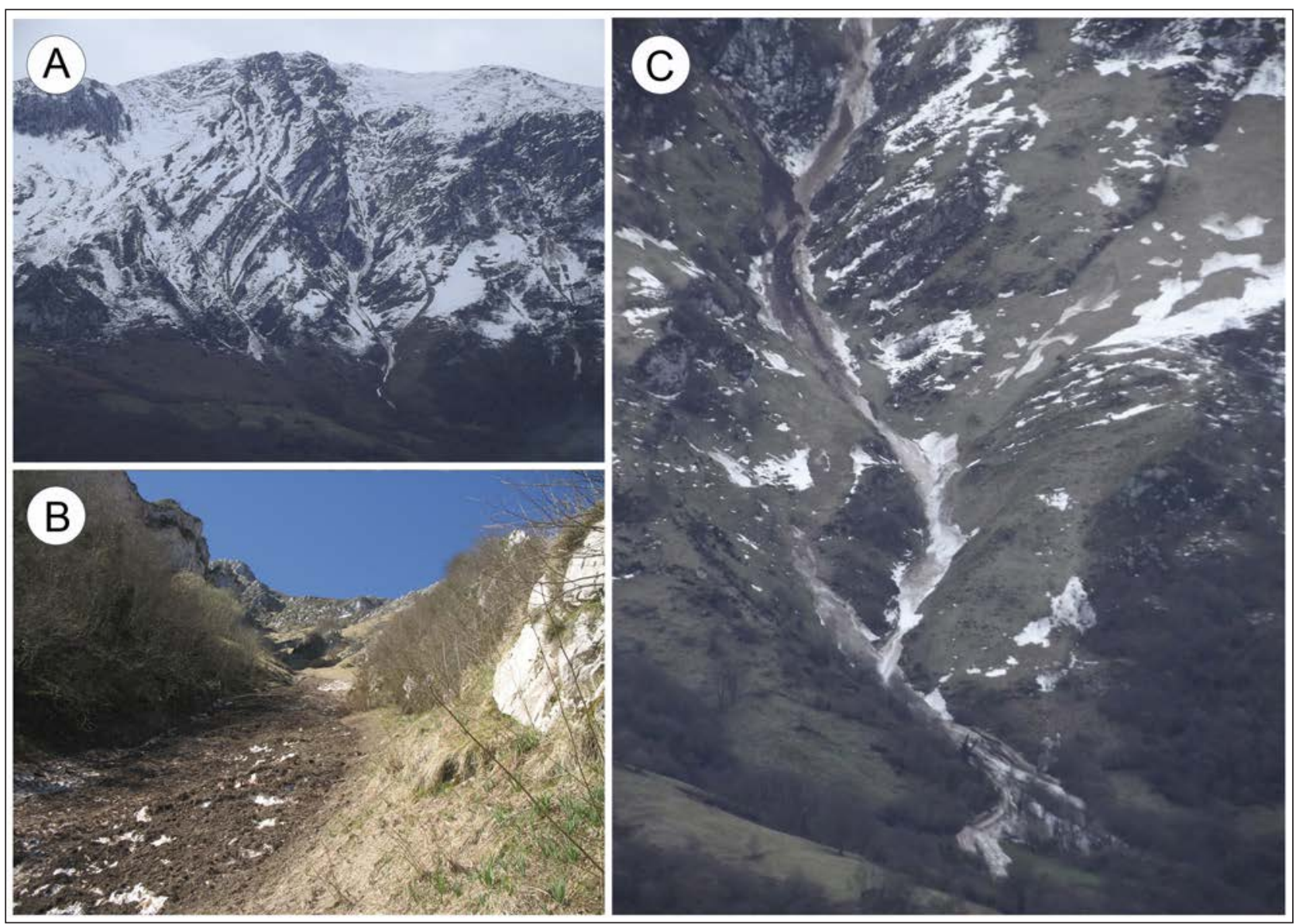

Figura 4: Canales y aludes de nieve en la vertiente oriental de la Sierra del Aramo. A) Redes dendríticas de canales de aludes (22 de febrero de 2016). B) Restos de alud de nieve húmeda en el canal de El Reguerón (30 de marzo de 2015). C) Detalle del canal de El Reguerón con aludes de nieve húmeda que descienden por debajo de los 700 m s.n.m. (16 de febrero de 2018).

Figure 4: Snow avalanches paths on the eastern slope of the Sierra del Aramo. A) Dendritic networks of avalanche tracks (February 22, 2016). B) Remains of wet snow avalanche in the El Reguerón path (March 30, 2015). C) Detail of the El Reguerón path with wet snow avalanches that descend below $700 \mathrm{~m}$ a.s.l. (February 16, 2018).

del Aramo y especialmente en la vertiente oriental, dado su emplazamiento a sotavento de los vientos del W. El otro factor que explica la actividad de los aludes de nieve es el gran desnivel de la ladera. En concreto, el $52,2 \%$ de la vertiente analizada presenta pendientes propensas para la formación de aludes, esto es, entre los 30 y $50^{\circ}$. Si excluyéramos del análisis la zona situada por debajo de $1.000 \mathrm{~m}$ la cifra ascendería al $63 \%$. Los declives de más de $50^{\circ}$ apenas alcanzan el $6,6 \%$, si bien, coinciden en su mayor parte con zonas de alimentación de canales o cabeceras de aludes. Todos estos datos cobran su verdadera relevancia si tenemos en cuenta que se trata de una montaña de media altitud y que, por encima de los $1.400 \mathrm{~m}$, sólo está el 9,7\% de la ladera. Precisamente es a esa altitud donde tiene lugar el punto de partida de los aludes de nieve más destacados, aunque también hay zonas de salida por debajo incluso de $1.100 \mathrm{~m}$. Finalmente, las áreas de llegada descienden, en el sector más dinámico, hasta los $700 \mathrm{~m}$.

Dos son los tipos más frecuentes de aludes de nieve que se desencadenan en la vertiente oriental: por un lado, los de nieve húmeda que descienden lentamente encauza- dos por los canales y, de otro, los de purga, en forma de coladas de nieve seca, que se producen en los tramos con mayor pendiente (superior a $50^{\circ}$ ) y a mayor velocidad. Los aludes de nieve húmeda tienen mayor frecuencia y capacidad destructiva y son los responsables de la eliminación de los árboles, los cuales son arrancados de raíz y arrastrados ladera abajo. Por el contrario, los aludes de purga son más rápidos y llevan a cabo una labor de mutilación, arrancando ramas y decapitando las copas de los árboles y arbustos (Figura 5).

Los aludes de nieve tienen desde el año 2000 una recurrencia anual, al menos, en los canales cuyas zonas de arranque están situadas por encima de los 1.400 m s.n.m. Por contra, los canales con el punto de partida situados por debajo de dicha altitud no están suficientemente abastecidos de nieve cada año y no son funcionales siempre. Así pues, los 100 canales documentados no están activos continuamente. En realidad, la mayor actividad acaece en los canales centrales (El Reguerón, el Arguixu La Yampa y El Espinial), en los que los aludes de nieve húmeda tienen lugar con una frecuencia de tres episodios anuales. 
Tabla 1. Características de los aludes de nieve de la Sierra del Aramo.

Table 1. Snow avalanches characteristics in the Sierra del Aramo.

\begin{tabular}{|c|c|c|c|c|c|c|c|}
\hline Grupo de canales & Tipo & Longitud & Desnivel & Pendiente & $\begin{array}{l}\text { Altitud } \\
\text { máx. }\end{array}$ & $\begin{array}{c}\text { Altitud } \\
\text { min. }\end{array}$ & Actividad \\
\hline \multicolumn{7}{|l|}{ Vertiente oriental } & (2010-2018) \\
\hline La Mostayal & Húmedos & $400-500$ & 400 & $30-50$ & 1.300 & 900 & 3 \\
\hline Bobies-Ories & Húmedos & $250-300$ & 350 & $30-50$ & 1.400 & 1.050 & 3 \\
\hline Fonfría & Húmedos & $200-250$ & 300 & $30-50$ & 1.400 & 1.100 & 3 \\
\hline Cueña les Cabres & Húmedos & $100-150$ & 200 & $30-50$ & 1.450 & 1.250 & 3 \\
\hline Cueña les Vaques & Húmedos & $600-800$ & 550 & $30-50$ & 1.550 & 1.000 & 4 \\
\hline La Trapada & Húmedos & $700-800$ & 600 & $30-50$ & 1.450 & 850 & 4 \\
\hline Cuesta la Balsa & Húmedos & $600-700$ & 600 & $30-50$ & 1.400 & 800 & 7 \\
\hline El Reguerón & Húmedos & $1200-1400$ & 900 & $30-50$ & 1.600 & 700 & 8 \\
\hline El Espinial & Húmedos & $1000-1050$ & 600 & $30-50$ & 1.300 & 700 & 8 \\
\hline Arguixu La Yampa & Húmedos & $1300-1350$ & 800 & $30-50$ & 1.500 & 700 & 7 \\
\hline La Muena & Húmedos & $400-450$ & 400 & $30-50$ & 1.250 & 850 & 4 \\
\hline Piedra del agua & Húmedos & $250-300$ & 350 & $30-50$ & 1.250 & 900 & 3 \\
\hline Cuesta Friera & Húmedos & $300-350$ & 400 & $30-50$ & 1.300 & 900 & 3 \\
\hline El Fresno & Húmedos & $150-200$ & 300 & $30-50$ & 1.200 & 900 & 3 \\
\hline Cuesta Pradiella & Húmedos & $200-250$ & 200 & $30-50$ & 1.350 & 1.150 & 3 \\
\hline Canal de Foz & Húmedos & $300-350$ & 250 & $30-50$ & 1.300 & 1.050 & 3 \\
\hline \multicolumn{8}{|l|}{ Vertiente occidental } \\
\hline Fontazán-Glayiru & Húmedos & $100-150$ & 200 & $30-50$ & 1.400 & 1.200 & 1 \\
\hline La Concha & Húmedos & $300-350$ & 250 & $30-50$ & 1.450 & 1.200 & 2 \\
\hline Pelitrón & Húmedos & $300-350$ & 200 & $30-50$ & 1.550 & 1.350 & 1 \\
\hline Champaza & Húmedos & $350-400$ & 350 & $30-50$ & 1.450 & 1.100 & 1 \\
\hline
\end{tabular}

Los efectos perturbadores de los aludes de nieve repercuten en la distribución y estructura de la cubierta forestal, puesto que mantienen la deforestación en la vertiente oriental de la Sierra del Aramo. En efecto, una amplia extensión de la ladera oriental, situada entre los 700 y los $1.600 \mathrm{~m}$, cubierta por formaciones vegetales herbáceas tendría que estar colonizada por una densa masa forestal, máxime si tenemos en cuenta la rápida regeneración natural que se ha producido en las montañas asturianas a partir de la segunda mitad del siglo XX. A pesar de que estos pastos tienen en su mayor parte un origen antrópico (pastoreo), muchos de los canales presentan una profundidad y anchura que denota una actividad prolongada durante el Cuaternario (Beato, 2018). En zonas marginales donde históricamente se han conservado pequeños bosques, los aludes de nieve se canalizan bajo la cubierta arbórea favoreciendo la apertura de corredores lineales, en los que también predomina el estrato herbáceo. No obstante, la composición taxonómica o florística de la franja forestal no se ha visto alterada por los aludes de nieve más allá de la conservación de paisajes tradicionalmente antropizados $\mathrm{y}$, por lo tanto, previamente transformados.
Las zonas de arranque de los aludes de nieve, que coinciden morfológicamente con nichos de nivación o con escarpes rocosos, se corresponden con afloramientos calcáreos en ocasiones subverticales, en los que se desarrolla básicamente una vegetación rupícola adaptada a las grietas de las rocas. Estas comunidades abiertas, de porte herbáceo y con árboles dispersos son sustituidas, en zonas con un mayor desarrollo edáfico, por formaciones cerradas de arbustos. Constituyen matorrales climácicos en las áreas más elevadas y abruptas, con suelos esqueléti$\cos$, si bien en el resto de la ladera representan una etapa de regresión de los bosques.

Las zonas de transición de los aludes presentan como rasgo común una cubierta vegetal pratense dominada por hemicriptófitos y geófitos de tipo heliófilo. Se desarrollan desde el piso colino hasta incluso el tramo inicial del subalpino. La composición florística varía en función de la profundidad, humedad, degradación y riqueza en bases del suelo. Así, son habituales los pastizales mesófilos sobre suelos profundos, los cervunales de suelos montanos descarbonatados y los herbazales nitrófilos. Son formaciones herbáceas de origen antrópico mantenidas fundamentalmente mediante pastoreo, que ocupan áreas poten- 

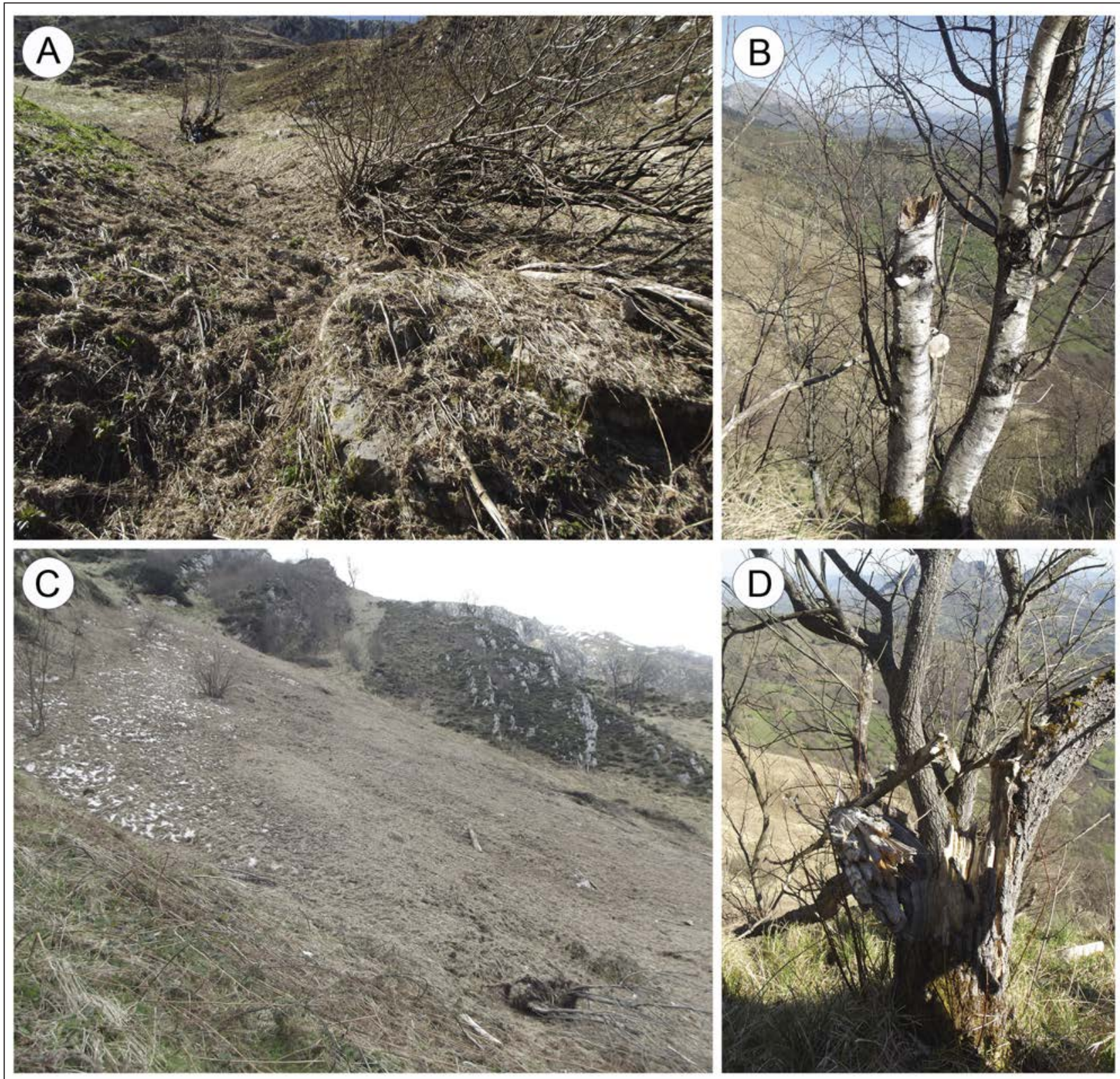

Figura 5: Efectos de los aludes de nieve sobre la vegetación en la Sierra del Aramo. A y C) Árboles arrancados y arrastrados por aludes de nieve húmeda (fotografías del 30 de marzo y 8 de abril de 2015). B y D) Árboles mutilados por aludes de nieve seca (fotografías del 8 de abril de 2015).

Figure 5: Effects of snow avalanches on vegetation in the Sierra del Aramo. A and C) Trees uprooted and mobilized by wet snow avalanches (photographs taken on March 30 and April 8, 2015). B and D) Trees mutilated by dry snow avalanches (photographs taken on April 8, 2015).

ciales de hayedos o robledales. Menos destacada es la extensión de los lastonares y los reductos de vegetación higrófila, en relación con factores naturales. Además, diferentes comunidades arbustivas van progresando por la vertiente, debido a una consabida menor presión ganadera, delimitando claramente las áreas afectadas por los aludes.

En las zonas de salida (runout) predomina la intercalación de pastos y prados de aprovechamiento continuado con herbazales en desuso. En este caso, el paisaje presenta un aspecto desolado, puesto que aparece cubierto de grandes bloques y cantos, restos arbóreos destruidos y arbustos dañados. También hay áreas colonizadas por formaciones arbustivas con ejemplares dispersos de acebos, avellanos y abedules que intentan prosperar.

La fisionomía de la cubierta vegetal en las semanas posteriores a la desaparición de los aludes de nieve pone en evidencia su papel en el mantenimiento de los pastiza- 
les, toda vez que las formaciones herbáceas por donde pasan quedan completamente arrasadas. El resultado es un brillo característico que contrasta con el color más oscuro de los helechos que quedan secos y tumbados tras ser aplastados bajo la cubierta nival estable. Además, por toda la zona sometida al impacto de la caída de los aludes hay avellanos arrancados de raíz y troncos de hayas, abedules y sauces cabrunos que intentaron colonizar infructuosamente el espacio deforestado que abarca una superficie de 370 ha (Figura 6).

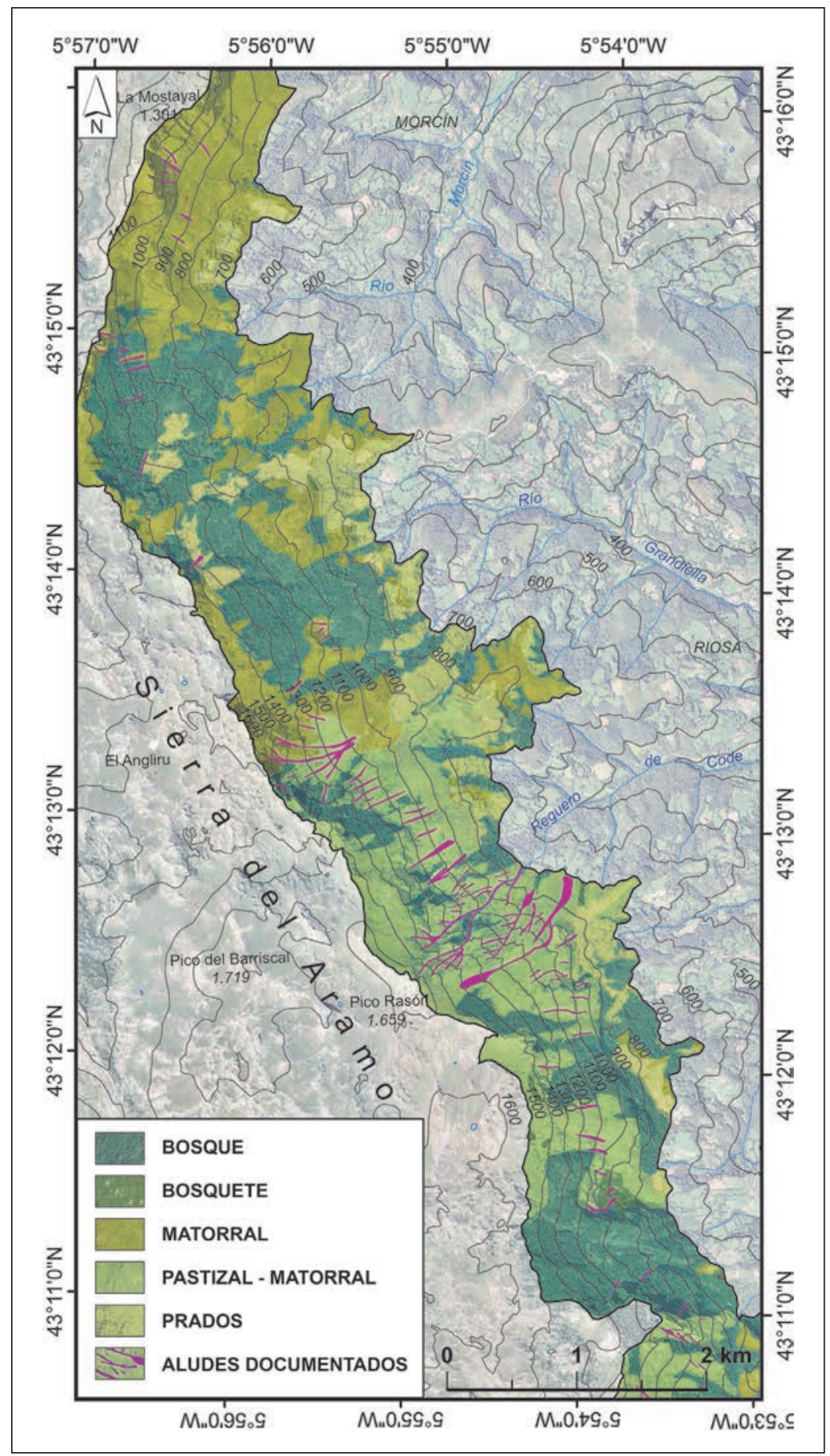

Figura 6: Formaciones vegetales y aludes de nieve documentados en la vertiente oriental de la Sierra del Aramo. Fuente: modificado a partir de Beato et al., 2017.

Figure 6: Vegetal formations and documented snow avalanches in the eastern slope of the Sierra del Aramo. Source: modificated from Beato et al., 2017. 


\section{2 • S. BEATO BERGUA, M. Á. POBLETE PIEDRABUENA, J. L. MARINO ALFONSO}

El matorral tiene una densidad y altura mayor en las áreas ganaderas abandonadas de forma más temprana y no afectadas por la actividad de los aludes de nieve, generando doseles impenetrables en los que la presencia de especies arbóreas dispersas augura el siguiente paso en el proceso de sucesión vegetal. Así lo demuestran las superficies crecientes ocupadas por Ilex aquifolium, en convivencia con Crataegus monogyna, Rhamnus alpina, Sorbus aria y Corylus avellana. Representan la etapa serial previa a la colonización del bosque climácico que se conserva en varias franjas de la ladera (hayedos y bosques mixtos caducifolios).

\section{Discusión}

La trascendencia de los aludes de nieve, tanto en intensidad y frecuencia, en las montañas medias del Macizo Asturiano no se limitan sólo a la Sierra del Aramo. En realidad, se producen en todas las montañas medias situadas entre $1.000-1.700 \mathrm{~m}$ y con pendientes entre $30^{\circ}$ y $50^{\circ}$, por lo que afectan potencialmente a una superficie de $173,1 \mathrm{~km}^{2}$ que representa el 9,6\% de las montañas medias del Macizo Asturiano (Figura 7).

A las múltiples funciones ecológicas que los bosques realizan en las vertientes montañosas hay que añadir la importante labor protectora al frenar la formación de los aludes de nieve (Gubler \& Rychetnik, 1991; Schneebeli \& Bebi, 2004), disminuir la distancia de salida (Teich et al., 2012a; Anderson \& McClung, 2012) y mitigar el impacto sobre las edificaciones e infraestructuras (Brang et al., 2006). Dicha labor de protección se materializa en la disminución de la velocidad y de la energía especialmente de los aludes de pequeño tamaño (Schneebeli \& Bebi, 2004) y de los que se desencadenan dentro del bosque conocidos como forest avalanches (Teich et al., 2012b). Por otro lado, hay que tener en cuenta que, desde la segunda mitad del siglo XX, como resultado del cambio de uso de suelo y el abandono del sistema de explotación tradicional, se ha producido una regeneración espontánea de los bosques, los cuales han experimentado una expansión notable en las montañas europeas como los Alpes (Gellrich et al., 2007), Pirineos (Vicente-Serrano et al., 2004), Cárpatos (Kozak, 2003) y Cordillera Cantábrica (Bengoa, 2011). Asimismo, algunos análisis de la pérdida de pastos y su transformación en matorral indican la importancia del aumento de las temperaturas en este proceso (Archer et al., 1995; Van Auken, 2000). Como resultado sería lógico inferir una reducción del número de aludes de nieve en dichas regiones montañosas. No obstante, la reforestación no se ha producido por igual en todas las vertientes, pues las solanas se hallan más deforestadas y el impacto

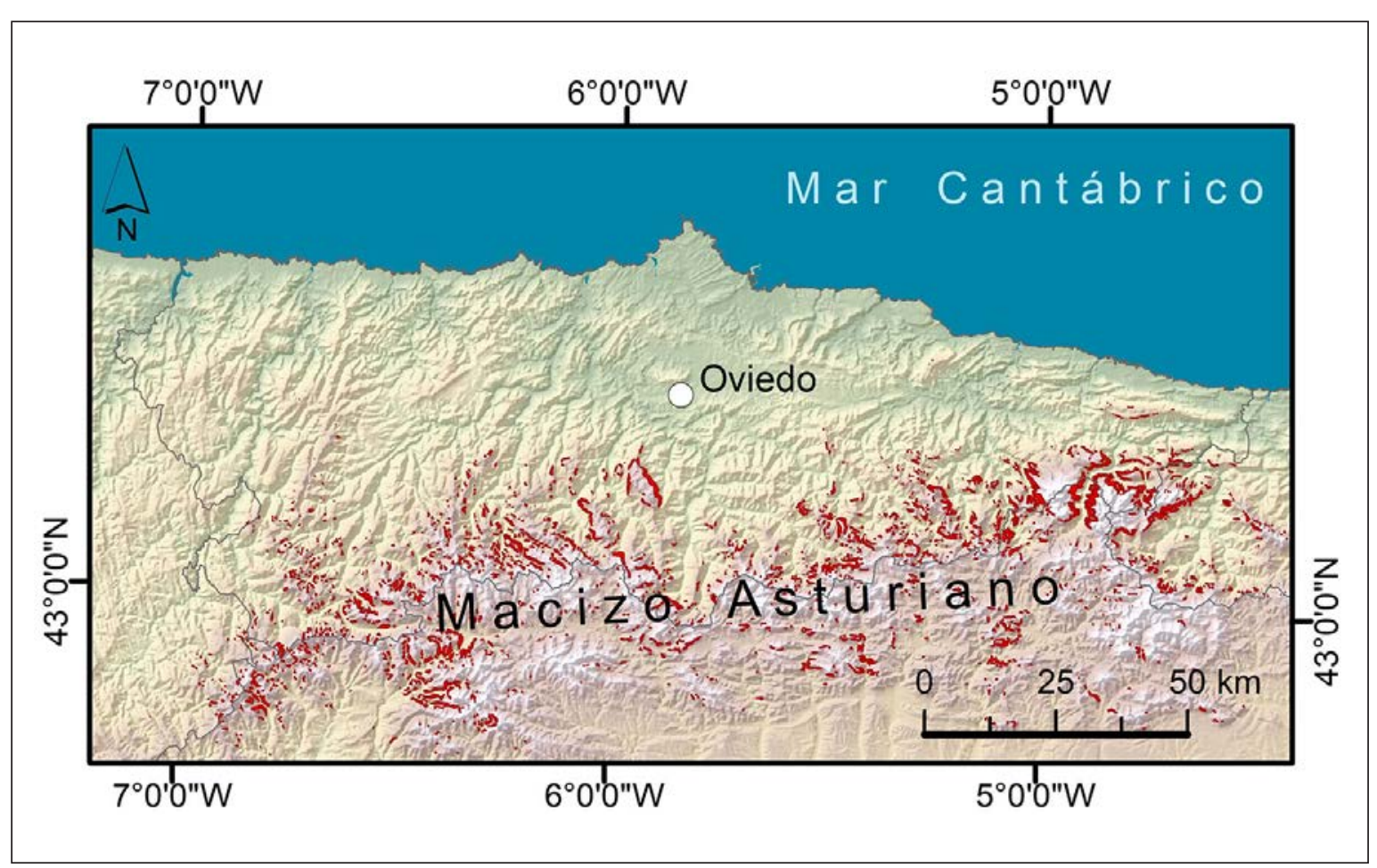

Figura 7: Mapa de susceptibilidad potencial de aludes de nieve en las montañas medias del Macizo Asturiano (altitudes entre $1.000 \mathrm{y}$ $1.700 \mathrm{~m}$ con pendientes entre $30^{\circ}$ y $50^{\circ}$ en color rojo). Fuente: Elaboración propia a partir del modelo digital del terreno y las bases topográficas digitales del Instituto Geográfico Nacional.

Figure 7: Mid-mountains prone to triggering snow avalanches in the Asturian Massif (1,000-1,700 m altitudes with 30-50 slope, in red). Source: Own elaboration from the DEM and the digital topographic bases of the Spanish National Geographic Institute. 
de los aludes de nieve es mayor, al tiempo que también depende del tipo de litología y fundamentalmente de la intensidad de las pendientes. De hecho, Bebi et al. (2009) muestran que la expansión forestal es únicamente relevante al limitar la formación de aludes de nieve sólo en ciertas condiciones topográficas, descartando su papel protector en aquellos bosques localizados en laderas muy escarpadas.

En el Macizo Asturiano, García-Hernández et al. (2017) señalan que la reforestación natural ha contribuido a la disminución de los daños producidos por los aludes de nieve. No obstante, aunque parezca paradójico indican que no hay una tendencia decreciente en el número de avalanchas dañinas, puesto que precisamente el periodo de 1960-2015 registró el porcentaje más alto de años con avalanchas dañinas (48\%) y además el porcentaje más alto de años en los que se registran más de cinco eventos $(13 \%)$. Hay que interpretar estos datos con cautela dado que el artículo citado se basa en fuentes de prensa no homogéneas desde 1900 y no tiene en cuenta factores como el incremento desde 1960 de la urbanización, infraestructuras y carreteras, así como de los medios de comunicación. En cualquier caso, en el Macizo Asturiano la disminución de los daños derivados de los aludes de nieve no implica en modo alguno una disminución de la peligrosidad de los aludes de nieve, especialmente, en las montañas medias. Entre las razones que explican la alta peligrosidad cabe destacar las siguientes: las dimensiones medianas de los recorridos de los aludes situados entre 300 y 400 m (Marquínez et al., 2003), el predominio de los aludes de nieve húmeda (Castañón 1984; Wozniak \& Marquínez, 2004; González \& Serrano, 2010) y que el desencadenamiento de los aludes de nieve tiene lugar en torno a $200 \mathrm{~m}$ por encima del límite del bosque. En efecto, las culminaciones de las vertientes permanecen deforestadas desde las aperturas de pastos neolíticas y del Bronce (Beato, 2018) y esto ha podido influir en la actividad de los aludes.

Por otra parte, los aludes de nieve en el Macizo Asturiano son muy frecuentes y se producen mayoritariamente en laderas deforestadas y con fuertes pendientes, por las que se han trazado abundantes infraestructuras como carreteras y pistas de montañas que además atraviesan las zonas de tránsito de los aludes; a lo que hay que añadir el intenso uso deportivo de las zonas de montaña (esquí de montaña, alpinismo, senderismo, etc.) y que las medidas protectoras frente a los aludes como viseras y barreras flexibles antialudes son muy escasas y recientes, las más antiguas de 2008 (Poblete et al., 2016). De hecho, Wozniak \& Marquínez (2004) señalan que 21 tramos de carreteras regionales, comarcales y locales son periódicamente dañados o cortados por los aludes de nieve en las montañas medias asturianas. En la Sierra del Aramo, la principal infraestructura afectada es la carretera de acceso a El Angliru, donde se registran habitualmente aludes de nieve en el último kilómetro de ascensión al puerto (Cueña les Cabres).

La incidencia del cambio climático en la intensidad y frecuencia de los aludes de nieve es en la actualidad obje- to de análisis y de debate entre los investigadores. En realidad, apenas se conoce el efecto del cambio climático sobre la actividad de los aludes de nieve (Teich et al., 2012b), no obstante, se ha observado una disminución en la altitud de la zona de salida (Eckert et al., 2010) unido a un incremento de la proporción relativa de los aludes húmedos (Martin et al., 2001). Efectivamente, el aumento de las temperaturas medias produce importantes contrastes térmicos en los periodos en los que se producen los temporales de nieve, contribuyendo a la fusión y a la generación de mantos nivales con estructuras inestables que favorecen el desencadenamiento de este tipo de aludes (Jamieson, 2006; Naaim et al., 2016; Schläppy et al., 2016; Muntán, 2016; Ballesteros-Cánovas et al., 2018).

Aunque en el Macizo Asturiano se aprecia una disminución del número de días con nevadas y de la nivosidad en términos generales, no obstante, las nevadas se producen concentradas en episodios de 5 a 6 días, siendo además muy copiosas (entre 30 y $40 \mathrm{~mm}$ en $24 \mathrm{~h}$ ). En este sentido, cabe destacar los 40,2 mm de nieve caídos en Aller (situada a 750 m s.n.m. en el Macizo Central Asturiano) el día 4 de febrero de 2018 y los $64,5 \mathrm{~mm}$ de nieve el 27 de octubre del mismo año en Pajares (situada a 1.480 m s.n.m. en el Macizo Central Asturiano). Si además tales nevazos van seguidos, días después, de precipitaciones en forma de lluvia o de la irrupción de aire cálido se generan fácilmente aludes de nieve húmeda, los cuales se originan cada vez con más frecuencia. Si estas copiosas y concentradas nevadas se producen sobre vertientes deforestadas, sometidas a elevada radiación (pues la mayoría están orientadas al Sur) y con pendientes muy escarpadas superiores a $30^{\circ}$ es fácil inferir que los aludes de nieve seguirán siendo frecuentes y de gran peligrosidad.

\section{Conclusiones}

La dinámica del paisaje en la Sierra del Aramo es el consecuencia de la interacción entre procesos naturales y antrópicos. Su cubierta forestal se está regenerando como resultado de la sustitución de un sistema de sobreexplotación agrosilvopastoril por otro basado en el abandono de las tierras y un aprovechamiento marginal semiextensivo. Es este un hecho evidente que se plasma en una expansión del bosque de 2.597 ha, constatada desde el declive de las estructuras socioeconómicas y territoriales a partir de los años 60 del siglo pasado.

No obstante, el crecimiento de la superficie forestal no se produce de manera homogénea y similar en todas las vertientes y franjas altitudinales. Entre otras razones debido a que la reforestación depende de factores no sólo culturales sino también naturales, entre los que destacan las condiciones climáticas y sus cambios por el calentamiento atmosférico y, por supuesto, la propia dinámica actual de las vertientes en la que la actividad perturbadora de los aludes de nieve juega un papel relevante. Efectivamente, el calentamiento atmosférico en el Macizo Asturiano ha originado una modificación de la nivosidad (disminución de la cantidad total de nieve caída y del número 
de días de nevadas) y de su comportamiento (concentración en temporales de varios días y con copiosas nevadas). Sin embargo, esto no ha repercutido en una merma de la actividad de los aludes de nieve, los cuales mantienen una alta recurrencia y elevada intensidad. Así, los aludes tanto de nieve seca como húmeda tienen repercusiones directas en las cubiertas vegetales de las montañas medias asturianas, especialmente en sus laderas orientales y meridionales. En concreto, la abundante nivosidad, concentrada en varios temporales entre noviembre y marzo, y la presencia de unas fuertes pendientes propician la recurrencia anual y una intensa capacidad destructiva de los aludes de nieve que impiden la regeneración forestal espontánea. En particular, los aludes de nieve húmeda, constantes en los últimos años, mantienen los pastos de los canales de la Sierra del Aramo, mientras que otras zonas afectadas por aludes de purga y nieve seca sufren daños en la vegetación e incluso en infraestructuras como la carretera de ascenso al puerto de El Angliru.

Por lo tanto, es necesario comprender mejor la relación entre los fenómenos naturales y culturales que tienen lugar en las montañas medias atlánticas, para abordar los cambios territoriales, paisajísticos y del patrimonio, así como los posibles riesgos asociados. Este trabajo corrobora la utilidad y eficacia de las investigaciones realizadas desde una perspectiva integrada y expone la importancia del trabajo de campo para detectar amenazas que pueden subestimarse, como la de los aludes de nieve en las montañas medias. Ciertamente, las declaraciones generales como que la reforestación disminuye el peligro de los aludes de nieve o que el cambio climático reduce el impacto de estos pueden subestimar lo que sucede a escala local, con repercusiones negativas para una adecuada y correcta planificación y gestión territorial.

\section{Referencias}

Aller, J., 1993. La estructura geológica de la Sierra del Aramo (Zona Cantábrica, NO de España). Trabajos de Geología, 19, pp. 3-15.

Álvarez, M.Á., Castro, M. de, Cruz, R., Gómez, A., Pérez, V. \& Stöll, H., 2009. Clima. In: Evidencias y efectos potenciales del cambio climático en Asturias (coord. R. Anadón). Consejería de Medio Ambiente y Ordenación del Territorio e Infraestructuras, pp. 30-65, Oviedo.

Anderson, G. \& McClung, D., 2012. Snow avalanche penetration into mature forest from timber-harvested terrain. Canadian Geotechnical Journal, 49(4): 477-484. https://doi. org/10.1139/t2012-018

Archer, S., Schimel, D.S. \& Holland, E.A., 1995. Mechanisms of shrubland expansion: land use, climate or CO2? Climatic Change, 29: 91-9. https://doi.org/10.1007/BF01091640

Arozena, M. E. \& Molina, P., 2000. Estructura de la vegetación. In: Metodología y práctica de la Biogeografía. (ed. G. Meaza). Ediciones del Serbal, pp. 77-147, Barcelona.

Ballesteros-Cánovas, J.A., Trappmann, D., Madrigal-González, J., Eckert, N. \& Stoffel, M., 2018. Climate warming enhances snow avalanche risk in the Western Himalayas. PNAS, 115 (13): 3410-3415. https://doi.org/10.1073/pnas.1716913115

Beato, S., 2018. El patrimonio natural de la Sierra del Aramo (Montaña Central Asturiana) y la evolución de su paisaje. Tesis Doctoral inédita. Universidad de Oviedo.
Beato, S., Poblete, M.Á. \& Marino, J.L., 2016. La expansión del matorral y su caracterización biogeográfica en la Sierra del Aramo (Montaña Central Asturiana, España). In: Avances en Biogeografía. Áreas de distribución: entre puentes y barreras (eds. J. Gómez, J. Arias, J.A Olmedo \& J.L. Serrano). Tundra, pp. 494-502, Granada.

Beato Bergua, S., Poblete Piedrabuena, M.Á. \& Marino Alfonso, J.L., 2017. El efecto de los aludes de nieve en las formaciones vegetales de la vertiente oriental de la Sierra del Aramo (Macizo Central Asturiano). In: Naturaleza, Territorio y Ciudad en un mundo global. Asociación de Geógrafos Españoles, pp. 70-79, Madrid. http://hdl.handle.net/10651/44606

Beato Bergua, S., Poblete Piedrabuena, M.Á. \& Marino Alfonso, J.L., 2018. Snow avalanche susceptibility in the eastern hillside of the Aramo Range (Asturian Central Massif, Cantabrian Mountains, NW Spain). Journal of Maps, 14(2): 373-381. https://doi.org/10.1080/17445647.2018.1480974

Bebi, P., Kulakowski, D. \& Rixen, C., 2009. Snow avalanche disturbances in forest ecosystems-State of research and implications for management. Forest Ecology and Management, 257(9): 1883-1892. https://doi.org/10.1016/j. foreco.2009.01.050

Bengoa, J., 2011. Cambios en el paisaje en la Cordillera Cantábrica (Asturias, Cantabria y Castilla y León) en los últimos 40 años: comparativa de superficies arboladas a partir del mapa forestal. In: La evolución del paisaje vegetal y uso del fuego en la Cordillera Cantábrica (coords. F. J. Ezquerra \& E. Rey). Junta de Castilla y León, pp. 185-198, Valladolid.

Brang, P., Schönenberger, W., Frehner, M., Schwitter, R., Thormann, J.-J. \& Wasser, B., 2006. Management of protection forests in the European Alps: an overview. Forest Snow and Landscape Research, 80: 23-44.

Braun-Blanquet, J., 1979. Fitosociología. Bases para el estudio de las comunidades vegetales. Blume. Madrid.

Burkard, A. \& Salm, B., 1992. Die Bestimmung der mittleren Anrissmächtigkeit do zur Berechnung von Fliesslawinen. Eidgenössisches Institut für Schnee- und Lawinenforschung. Davos.

Butler, D.R., 1985. Vegetational and geomorphic change on snow avalanche paths, Glacier National Park, Montana, USA. The Great Basin Naturalist, 45(2): 313-317.

Castañón, J.C., 1984. Sobre el modelado originado por los aludes de nieve en el Prau del Albo (Alto Huerna, Asturias). Ería. Revista de Geografia, 6: 106-112.

Chueca, J. \& Julián, A., 2010. Cartografía de zonas probables de salida de aludes en el Alto Gállego (Pirineo Central Aragonés) mediante el empleo de Sistemas de Información Geográfica. Cuadernos de Investigación Geográfica, 36(1): 27-41.

Eckert, N., Parent, E., Kies, R. \& Baya, H., 2010. A spatio-temporal modeling framework for assessing the fluctuations of avalanche occurrence resulting from climate change: application to 60 years of data in the northern French Alps. Climatic Change, 101(3-4): 515-553. https://doi.org/10.1007/ s10584-009-9718-8

Fernández-Cañadas, J.A., 2014. Los aludes de nieve en el Macizo de Peñalara. AEMET. Madrid.

Furdada, G., Martí, G., Oller, P., García, C., Mases, M. \& Vilaplana, J.M., 1995. Avalanche mapping and related G.I.S. applications in the Catalan Pyrenees. Survey in Geophysics, 16(5-6): 681-693. https://doi.org/10.1007/BF00665748

García, C., Martí, G., Oller, P., Moner, I., Gavaldà, J., Martínez, P. \& Peña, J.C., 2009. Major avalanches occurrence at regional scale and related atmospheric circulation patterns in the Eastern Pyrenees. Cold Regions Science and Technology, 59: 106-118. https://doi.org/10.1016/j.coldregions.2009.07.009

García-Hernández, C., Ruiz-Fernández, J., Sánchez-Posada, C., Pereira, S., Oliva, M. \& Vieira, G., 2017. Reforestation and 
land use change as drivers for a decrease of avalanche damage in mid-latitude mountains (NW Spain). Global and Planetary Change, 153: 35-50. https://doi.org/10.1016/j. gloplacha.2017.05.001

Gellrich, M., Baur, P., Koch, B. \& Zimmermann, N.E., 2007. Agricultural land abandonment and natural forest re-growth in the Swiss mountains: A spatially explicit economic analysis. Agriculture, Ecosystems and Environment, 118: 93-108. https://doi.org/10.1016/j.agee.2006.05.001

Giacona, F., Eckert, N., Mainieri, R., Martin, B., Corona, Ch., Lopez-Saez, J., Monnet J-M, Naaim, M. \& Stoffel, M., 2018. Avalanche activity and socio-environmental changes leave strong footprints in forested landscapes: a case study in the Vosges medium-high mountain range. Annals of Glaciology. https://doi.org/10.1017/aog.2018.26

González, J.J. \& Serrano, E., 2010. La nieve en los Picos de Europa: implicaciones geomorfológicas y ambientales. Cuadernos de Investigación Geográfica, 36(2): 61-84. http://dx.doi.org/10.18172/cig.1238

Gubler, H. \& Rychetnik, J., 1991. Effects of forest near the timberline on avalanche formation. International Association of Hydrological Sciences Publication, 205: 19-38.

Heffernan, O., 2018. Coming down the tracks. Nature Climate Change, 8: 937-939.

INDUROT, 1994. Cartografía temática ambiental. Mapa de vegetación. Escala 1:25.000. Consejería de Medio Ambiente, Ordenación del Territorio e Infraestructuras del Gobierno del Principado de Asturias.

Jamieson, B., 2006. Formation of refrozen snowpack layers and their role in slab avalanche release, Reviews of Geophysics, 44: RG2001, https://doi.org/10.1029/2005RG000176

Kozak, J., 2003. Forest cover change in the Western Carpathians in the past 180 years: A case study in the Ottawa region in Poland. Mountain Research and Development, 23(4): 369375. https://doi.org/10.1659/0276-4741(2003)023[0369:FC CITW]2.0.CO;2

Kulakowski, D., Bebi, P. \& Rixen, C., 2011. The interacting effects of land use change, climate change and suppression of natural disturbances on landscape forest structure in the Swiss Alps. Oikos, 120: 216-225. https://doi. org/10.1111/j.1600-0706.2010.18726.x

Lallana, V. \& González, R., 2012. Transformación del paisaje forestal en un sector de la montaña cantábrica central: el Valle de Polaciones (Cantabria). In: Las zonas de montaña: gestión y diversidad (coords. R. Cunill, A. Pèlachs, R. Pérez-Olbiol \& J.M. Soriano), Departament de Geografía de la Universitat Autònoma de Barcelona, pp. 402-407, Barcelona.

Lasanta, T., Vicente-Serrano, S. \& Cuadrat-Prats, J.M., 2005. Mountain Mediterranean landscape evolution caused by the abandonment of traditional primary activities: a study of the Spanish Central Pyrenees. Applied Geography, 25: 47-65. https://doi.org/10.1016/j.apgeog.2004.11.001

Luckman, B.H., 1978. Geomorphic work of snow avalanches in the Canadian Rocky Mountains. Artic and Alpine Research, 10: $261-276$

MAPAMA (Dirección General de Desarrollo Rural), 2018. Mapa Forestal de España de máxima actualidad 1:25.000 (MFE25). Ministerio para la Transición Ecológica. Disponible en https://www.miteco.gob.es/es/cartografia-y-sig/ ide/descargas/biodiversidad/mfe.aspx

Martin, E., Giraud, G., Lejeune, Y. \& Boudart, G., 2001. Impact of a climate change on avalanche hazard. Annals of Glaciology, 32: 163-167. https://doi.org/10.3189/172756401781819292

Marquínez, J., Menéndez, R., Lastra, J., Fernández, E., Jiménez-Alfaro, B., Wozniak, E., Fernández, S., García, J., García, P., Álvarez, M.A., Lobo, T. \& Adrados, L., 2003. Riesgos Naturales en Asturias. Principado de Asturias-INDUROT-KRK Ediciones. Oviedo.
Martínez, L.C., 2016. Los paisajes de la alta montaña central de Asturias. Ediciones Universidad de Valladolid. Valladolid.

McClung, D.M. \& Schaerer, P., 2006. The Avalanche Handbook. (3th ed.). The Mountaineers Books. Seattle.

Molinillo, M., Lasanta, T. \& García-Ruiz, J.M., 1997. Managing mountainous degraded landscapes after farmland abandonment in the Central Spanish Pyrenees. Environmental Management, 21(4): 587-598. https://doi.org/10.1007/ s002679900051

Muntán, E., García, C., Oller, P., Martí, G., García, A. \& Gutiérrez, E., 2009. Reconstructing snow avalanches in the Southeastern Pyrenees. Natural Hazards Earth System Sciences, 9: 1599-1612. https://doi.org/10.5194/nhess-9-1599-2009

Muntán, E., Oller, P. \& Gutiérrez, E., 2010. Tracking past snow avalanches in the SE Pyrenees. In: Tree Rings and Natural Hazards, a State-of-the-Art (eds. M. Stoffel, M. Bollschweiler, D.R. Butler, \& B.H. Luckman). Springer, pp. 47-50. Heidelberg, Berlin, New York. https://doi.org/10.1007/978-90-481-8736-2

Muntán, E., 2016. Snow avalanches in the Pyrenees: Dendrochronological dating, dendrogeomorphological mapping and detection of past snow-avalanche seasons at a regional scale. Tesis Doctoral inédita. Universitat de Barcelona.

Muñoz, J., 1982. Geografía de Asturias. Ayalga Ediciones. Oviedo.

Muñoz, J. \& Sanz, C., 1995. Las Montañas. Guía Física de España. Alianza Editorial. Madrid.

Muñoz Trigo, P., 1988. Prevención y defensa contra aludes, aplicación práctica al Pirineo aragonés. Tesis Doctoral inédita. Universidad Politécnica de Madrid, Escuela Superior de Ingenieros de Montes, Madrid e Instituto Pirenaico de Ecología (CSIC), Jaca.

Naaim, M., Eckert, N., Giraud, G., Faug, T., Chambon, G., Naaim-Bouvet, F. \& Richard, D. 2016. Impact du réchauffement climatique sur l'activité avalancheuse et multiplication des avalanches humides dans les Alpes françaises. La Houille Blanche, 6: 12-20. https://doi.org/10.1051/lhb/2016055

Pattern, R.S. \& Knight, D.H., 1994. Snow Avalanches and Vegetation Pattern in Cascade Canyon, Grand Teton National Park, Wyoming, USA. Artic and Alpine Research, 26(1): 35-41. https://doi.org/10.2307/1551874

Poblete, M.A., Beato, S. \& Marino, J.L., 2016. Los aludes de nieve en el Alto Aller: su incidencia en la carretera AS-253 del Puerto de San Isidro (Macizo Central Asturiano). In: Comprendiendo el relieve: del pasado al futuro (eds. J.J. Durán, M. Montes, A. Robador \& A. Salazar). Instituto Geológico y Minero de España, pp. 751-758, Madrid.

Rixen, C., Haag, S., Kulakowski, D. \& Bebi, P., 2007. Natural avalanche disturbance shapes plant diversity and species composition in subalpine forest belt. Journal of Vegetation Science, 18: 735-742. https://doi.org/10.1111/j.1654-1103.2007.tb02588.x

Roura-Pascual, N., Pons, P., Etienne, M. \& Lambert, B., 2005. Transformation of a rural landscape in the Eastern Pyrenees between 1953 and 2000. Mountain Research and Development, 25(3): 252-261. https://doi.org/10.1659/0276-4741(20 05)025[0252:TOARLI]2.0.CO;2

Santos, J., Redondo, J.M., Gómez, A. \& González, R.B., 2010. Los aludes de nieve en el Alto Sil (Oeste de la Cordillera Cantábrica, España). Cuadernos de Investigación Geográfica, 36(1): 7-26. https://doi.org/10.18172/cig.1224

Sanz-Elorza, M., Dana, E.D., González, A. \& Sobrino, E., 2003. Changes in the high-mountain vegetation of Central Iberian Peninsula as a probable sign of global warming. Annals of Botany, 92: 273-280. https://doi.org/10.1093/aob/mcg130

Sawyer, C.F. \& Butler, D.R., 2006. A chronology of high-magnitude snow avalanches reconstructed from archived newspapers. Disaster Prevention and Management, 15(2): 313324. https://doi.org/10.1108/09653560610659856 
Schläppy, R., Jomelli, V., Eckert, N., Stoffel, M., Grancher, D., Brunstein, CH., Corona, D. \& Deschatres, M., 2016. Can we infer avalanche-climate relations using tree-ring data? Case studies in the French Alps. Regional Environmental Change, 16: 629-642. https://doi.org/10.1007/s10113-015-0823-0

Schneebeli, M. \& Bebi, P., 2004. Snow and avalanche control. In: Encyclopedia of Forest Sciences (eds. J. Burley, J. Evans \& J.A.Youngquist). Elsevier, pp. 397-402, Oxford. https:// doi.org/10.1016/B0-12-145160-7/00271-4

Schweizer, J., Jamieson, J.B. \& Schneebeli, M., 2003. Snow avalanche formation. Reviews of Geophysics, 41(4): 2-25. https://doi.org/10.1029/2002RG000123

Serrano, E., Gómez, M. \& Pisabarro, A., 2016. Nieve y riesgo de aludes en la Montaña Cantábrica: el alud de Cardaño de Arriba, Alto Carrión (Palencia). Polígonos. Revista de Geografia, 28: 239-264. http://dx.doi.org/10.18002/pol. v0i28.4295

Teich, M., Bartelt, P., Gret-Regamey, A. \& Bebi, P., 2012a. Snow avalanches in forested terrain: influence of forest parameters, topography, and avalanche characteristics on runout distance. Artic, Antartic, and Alpine Research, 44(4): 509-519. https://doi.org/10.1657/1938-4246-44.4.509

Teich, M., Marty, C., Gollut, C., Grêt-Regamey, A. \& Bebi, P., 2012 b. Snow and weather conditions associated with avalanche releases in forests: Rare situations with decreasing trends during the last 41 years. Cold Regions Science and
Technology, 83-84: 77-88. https://doi.org/10.1016/j. coldregions.2012.06.007

Vada, J.A., Frochoso, M. \& Vilaplana, J.M., 2012. Evaluación y cartografía del riesgo de aludes en el camino PR-PNPE 21 de acceso a la Vega de Urriellu, Picos de Europa (Noroeste de España). Cuaternario y Geomorfología, 26(1-2): 29-47.

Van Auken O.W., 2000. Shrub-Invasions of North American Semiarid Grass-lands. Annual Reviews of Ecology and Sytematics, 31: 197-215. https://doi.org/10.1146/annurev. ecolsys.31.1.197

Vicente-Serrano, S.M., 2001. El papel reciente de la ganadería extensiva de montaña en la dinámica del paisaje y en el desarrollo sostenible: el ejemplo del valle de Borau. Publicaciones del Consejo de Protección de la Naturaleza de Aragón. Zaragoza.

Vicente-Serrano, S.M., Lasanta, T. \& Romo, A., 2004. Analysis of spatial and temporal evolution of vegetation cover in the Spanish Central Pyrenees: role of human management. Environmental Management, 34: 802-818. https://doi. org/10.1007/s00267-003-0022-5

Wozniak, E. \& Marquínez, J., 2004. Evaluación de la susceptibilidad por aludes de nieve a escala regional: el caso de Asturias. In: Riesgos Naturales y Antrópicos en Geomorfología (eds. G. Benito \& A. Díez). Consejo Superior de Investigaciones Científicas y Universidad de Castilla-La Mancha, pp. 509-518, Toledo. 